aUniversidade Estadual de Maringá, Departamento de Química, campus sede, Avenida Colombo 5790, CEP 87020-900, Maringá-PR, Brasil.

'Universidade Estadual de Maringá, Programa de pós-graduação em Ciência de Alimentos. Avenida Colombo 5790, CEP 87020-900, Maringá-PR, Brasil.

*Email: jesuivv@gmail.com

Recebido em: 8 de Abril de 2021

Aceito em: 27 de Julhor de 2021

Publicado online: 17 de Novembro de 202

\section{Partition of Lipid Classes in Extra Virgin Olive Oil via Classic Liquid Chromatography and Subsequent Characterization Employing GC-FID and ESI-MS}

\author{
Partição de Classes de Lipídios em Azeite de Oliva Extra Virgem \\ via Cromatografia Líquida Clássica e Caracterização Subsequente \\ Empregando GC-FID e ESI-MS
}

\author{
Patrícia M. Souza, ${ }^{a(1)}$ Patrícia D. S. Silva, ${ }^{a(1)}$ Geovane A. R. Silva, ${ }^{a}$ Victor H. M. Cruz, ${ }^{a}$ Eloize S. \\ Alves, $^{b(1)}$ Matheus C. Castro, ${ }^{a(1)}$ Oscar O. S. Júnior, ${ }^{a, b}$ (1) Jesuí V. Visentainera, ${ }^{a, b} *$
}

\begin{abstract}
Olive oil is daily consumed due to its exceptional properties, such as pleasant organoleptic characteristics, oxidative stability, and chemical composition. Moreover, the edible oil has a high content of several compounds, for example, hydrocarbons, tocopherols, aliphatic alcohols, volatile phenolic compounds, pigments, lipids, among others. In order to properly separate, identify, and quantify all lipid species present in olive oil, adequate analytical methods are indispensable. Therefore, this study aimed to employ classic liquid chromatography to separate, identify and quantify the lipid classes in olive oil employing classic liquid chromatography (CLC), gas chromatography with flame ionization detector (GC-FID), and direct infusion by electrospray ionization mass spectrometry (ESI-MS). The results indicated a higher percentage of monounsaturated fatty acids (MUFA) in the non-polar lipid fraction than in the polar fraction, which in turn displayed higher content of saturated fatty acids (SFA) due to its greater affinity towards the stationary phase, while the unsaturated fatty acids (UFA) displayed stronger interactions with the mobile phase. These results concur with those obtained by ESI-MS, which proved possible the partition of polar and non-polar lipid fractions of olive oil by CLC, and that the major triacylglycerols (TAG) of olive oil were identified in the neutral lipid fraction.
\end{abstract}

Keywords: Fatty acids; triacylglycerols; classic liquid chromatography; gas chromatography; mass spectrometry.

\section{Introduction}

Olea Europaea, commonly referred as olive tree, is one of the oldest trees discovered, mainly cultivated for its fruits, from which olive oil is extracted. The edible oil is consumed on a daily basis owing to the sheer volume of articles that sustain its outstanding properties, provided by organoleptic characteristics, oxidative resistance, and chemical composition, which lead to olive oil being used as a potential treatment for diseases such as stomach ulcers and skin disorders. ${ }^{1-3}$

Due to its nutritional benefits and unique sensorial characteristics, olive oil (OO) is widely consumed worldwide. A statistical report by Espadas-Aldan et al. (2019) and IOC (2021), stated that OO consumption skyrocketed between 2000 and 2017 , peaking at $2.76 \times 10^{6}$ tons, indicating a $5.2 \%$ growth in consumption compared to 2000 . To supply this overwhelming demand for $\mathrm{OO}$, the production rates of this vegetable oil also greatly increased ${ }^{4-5}$

A report by the International Olive Council (IOC) stated that between 2017 and 2018 the global production of $\mathrm{OO}$ increased $29.4 \%$, peaking at $3.314 \times 10^{6}$ tons in $2018^{4-5}$. OO is primarily cultivated in the Mediterranean bay, which is responsible for $95 \%$ of the world's production of this vegetable oil. Furthermore, because of adequate climatic conditions, other regions, for example, North Africa, North America, South America, and Asia also invested in OO production. South America, specifically, has a few countries such as Argentina, Chile, and Uruguay who have been cultivating OO for several years. However, Brazil has only recently started investing in OO production, with only three states actively producing the vegetable oil: Minas Gerais, São Paulo, and Rio Grande do Sul. ${ }^{6-7}$

Nevertheless, the investments of Brazil in Olive tree cultivation positively influenced national agriculture and agribusiness. According to the Instituto Brasileiro de Azeitonas, in 2018, the production of OO in Brazil increased 42.8\% compared to 2017, reaching 150.000 L of OO, thus signaling a growing trend in the national production. ${ }^{8-9}$ 
OO has a complex chemical composition attributable to the several different compounds in the oil, for instance, hydrocarbons, tocopherols, aliphatic alcohols, volatile phenolic compounds, pigments, lipids, and others. Lipids, the major compounds of $\mathrm{OO},{ }^{10}$ are defined as a broad and complex group of organic compounds typically soluble in organic solvents and insoluble in water. Furthermore, lipids can be divided into non-polar lipids, such as triacylglycerols (TAGs), diacylglycerols (DAGs), monoacylglycerols (MAGs), sterols, wax, and fatty acids (FAs), and polar lipids, for instance, phospholipids and glycolipids. ${ }^{11-12}$

Despite the wide range of lipids in OO, TAGs are the major components of edible oil and represent $99 \%$ of the whole oil composition. ${ }^{13}$ TAGs molecules consist of three FAs residues, the main lipid class in living beings, attached to a glycerol backbone. In Extra virgin olive oil (EVOO), the major FAs are oleic acid (18:0, 55-83\%), followed by palmitic (16:0, 7.5\%-20\%), linoleic (18:2n-6, 3.5-2.1\%), and stearic acids (18:0 0.5\%-5\%), respectively. ${ }^{14}$ However, changes in the FA composition of EVOO could be observed due to the influence of several agricultural conditions, for instance, quality of soil, latitude, weather, and fruit quality and ripeness. ${ }^{2,15}$

Adequate analytical methods are indispensable to efficiently analyze lipids in EVOO. Gas chromatography with a flame ionization detector (GC-FID), and direct infusion by electrospray ionization (ESI-MS) are the generally employed techniques to analyze the lipid profile of EVOO. ${ }^{15-17}$ Nevertheless, both techniques require a sample preparation step. Typically, simple liquid extraction is employed as a sample preparation technique. The main objective of the extraction step is to separate the target analytes from other compounds present in the matrix. Among several extraction techniques, liquid-liquid extraction has been widely utilized due to numerous advantages, for instance, simplicity, low cost, and a myriad of extraction solvents available for extraction, among others. Conversely, the technique has significant drawbacks, such as low recovery rates for target analytes due to the numerous steps carried out during extraction (stirring, filtration, evaporation, among others). Furthermore, some extraction solvents employed are substantially toxic, which increases risks to the analyst and environment. ${ }^{18}$

Briefly, during liquid-liquid extraction, target analytes are transferred from the sample to the extracting solvent by a partition mechanism, thus allowing further identification and quantification of extracted analytes. ${ }^{19}$ However, classic liquid chromatography (CLC) can also be utilized as a sample preparation technique to partition the lipid classes in extra virgin olive oil. ${ }^{20} \mathrm{CLC}$ is performed in a glass column filled with a stationary phase in which the target compounds are separated, under atmospheric pressure, in theoretical plates created while the mobile phase, driven by gravity, permeates the column. ${ }^{21}$ This technique is widely utilized to isolate and purify compounds in extremely complex matrices. Although CLC has attractive advantages, for example, low cost of operation when compared to more recently developed extraction techniques, and simplicity, some drawbacks compromise the technique's popularity. For instance, CLC is time-consuming as it depends on gravity, plus the technique requires further auxiliary methods. ${ }^{22}$

Previous studies have already proposed the usage of other methods to analyze OO, such as Olmo-García et al. (2018), ${ }^{23}$ Bajoub et al. (2015), ${ }^{24}$ Capriotti et al. (2014), ${ }^{25}$ and Tasioula-Margari and Okogeri et al. (2001). ${ }^{26}$ Still, to our knowledge, no paper has investigated the use of CLC to separate the lipid classes of OO.

Although the oil's lipid fractions can be analyzed by gas chromatography with a flame ionization detector (GCFID), lipids need to undergo a derivatization step before instrumental analysis to increase their volatility and thermal stability. ${ }^{21}$ Mass spectrometry (MS) is a major separation and characterization technique, extensively used to analyze a broad spectrum of molecules as a result of the technique's ability to detect, characterize and separate molecules based on their mass and charge $(\mathrm{m} / \mathrm{z}) .^{27}$ Besides, the technique speed, sensitivity, and selectivity are crucial for the characterization of vegetable oils. ${ }^{15,28-30}$ Hence, this study aimed to partition, identify, and quantify the lipid classes in EVOO using CLC, GC-FID, and ESI-MS, respectively.

\section{Material and Methods}

\subsection{Reagents and materials}

Methanol, acetone, n-heptane, potassium hydroxide, and chloroform were purchased from Synth (São Paulo, Brazil). Analytical standard methyl tricosanoate (23:0me), and ammonium formate (97\%) were acquired from SigmaAldrich (Darmstadt, Germany). GC-FID analysis was performed using analytical grade reagents. HPLC-grade solvents were used for ESI-MS analysis.

\subsection{Samples}

EVOO was purchased from the local market in MaringáPR, Brazil. The oil was stored in its original package, under refrigeration $\left(6\right.$ to $\left.10^{\circ} \mathrm{C}\right)$, sheltered from light until analysis.

\subsection{Separation of lipid classes in EVOO by classic liquid chromatography}

Aliquots of EVOO (2g) were divided into non-polar and polar lipid fractions using CLC, following the procedure proposed by Johnston et al. (1983)..$^{20}$ The column utilized for separation has $30 \mathrm{~cm}$ in length and an internal diameter of $2 \mathrm{~cm}$. Silica gel (70-230 mesh, Merck), rinsed with methanol followed by chloroform, was used as stationary phase.

The mixture of solvent and adsorbent was placed on a magnetic stirrer for 1 hour for each new solvent added. After stirring, a vacuum pumped rotary evaporator was utilized 
to evaporate solvents in the mixture. Then, the adsorbent was placed in a desiccator until completely dried. Lastly, a slurry prepared with $60 \mathrm{~g}$ of adsorbent and a small volume of chloroform, was carefully poured into the column until $16 \mathrm{~cm}$ of the column was filled.

Elution of the lipid fractions was performed as follows:

1) Fraction 01: Non-polar lipids were eluted using $200 \mathrm{~mL}$ of a $20 \%$ acetone/chloroform solution.

2) Fraction 02: Polar lipids were eluted with $200 \mathrm{~mL}$ of methanol.

The lipid content of each eluted fraction was determined gravimetrically. Solvents were evaporated using a rotary evaporator. A small volume of chloroform was utilized to transfer the lipid fractions to a previously weighted flatbottomed flask. The percentage of each lipid fraction was calculated based on the volume of lipid poured into the column.

\subsection{Esterification/ Transesterification methodology}

Fatty acid esterification and transesterification reactions were performed according to ISO $5509^{31}$ methodology. First, $0.1 \mathrm{~g}$ of lipids and $2 \mathrm{~mL}$ of $\mathrm{n}$-heptane were added to a previously weighted test tube. The mixture was stirred for $1 \mathrm{~min}$ in a magnetic stirrer. Then, $2 \mathrm{~mL}$ of esterification solution $\mathrm{KOH} / \mathrm{MeOH}$ was added, and stirring maintained for $2 \mathrm{~min}$. Lastly, $0.5 \mathrm{~mL}$ methyl tricosanoate (23:0me) was added to the test tube, and the mixture was centrifuged to assist phase separation. After phase separation was completed, the upper phase was collected and injected into a gas chromatograph equipped with a flame ionization detector.

\subsection{Fatty acid composition by GC-FID}

Chromatographic analysis was performed in a Shimadzu gas chromatograph equipped with a flame ionization detector (FID), split/splitless injector, and a fused silica capillary column GC-2010 Plus (Select FAME, $100.0 \mathrm{~m}$ long, $0.25 \mathrm{~mm}$ internal diameter, and $0.25 \mu \mathrm{m}$ thin film of cyanopropyl as stationary phase). Fatty acid methyl esters (FAMEs) were analyzed in triplicate using the following conditions, Table 1.

Table 1. Column oven temperature program

\begin{tabular}{|c|c|c|}
\hline Rate $\left({ }^{\circ} \mathrm{C} \mathrm{min}-1\right)$ & Temperature $\left({ }^{\circ} \mathbf{C}\right)$ & Hold Time (min) \\
\hline- & 165.0 & 7.00 \\
\hline 4.00 & 185.0 & 3.00 \\
\hline 6.00 & 235.0 & 2.67 \\
\hline
\end{tabular}

Gas flows of $1.2 \mathrm{~mL} \mathrm{~min}^{-1}$ and $30 \mathrm{~mL} \mathrm{~min}^{-1}$ were utilized for carrier $\left(\mathrm{H}_{2}\right)$ and make-up $\left(\mathrm{N}_{2}\right)$ gases, respectively. In the detector, gas flows of $30.0 \mathrm{~mL} \mathrm{~min}^{-1}$ and $300.0 \mathrm{~mL} \mathrm{~min}^{-1}$ of $\mathrm{H}_{2}$ and synthetic air, respectively, were employed to feed the detector's flame. $1.0 \mu \mathrm{L}$ of samples were injected into the gas chromatograph using a 40:1 split ratio. FAMEs were identified by comparing the retention times of the sample's constituents with those of the Sigma FAMEs analytical standard. All samples were analyzed in triplicate.

\subsection{TAG profile by direct infusion ESI-MS}

TAGs with ammonium adducts $(+18,03 \mathrm{~m} / \mathrm{z})$ in EVOO's lipid fractions were detected by triple quadrupole mass spectrometer Xevo TQD ${ }^{\mathrm{TM}}$ (Waters, Massachusetts, United States) equipped with a Waters Zspray TM (Milford, Massachusetts, United States) electrospray ionization source.

The analysis was carried out as described by Silveira et al (2017). ${ }^{15} 0.05 \mathrm{~mL}$ of oil was diluted in $0.95 \mathrm{~mL}$ of chloroform, then an aliquot of $0.005 \mathrm{~mL}$ of this solution was collected and mixed with $1.0 \mathrm{~mL}$ of a methanol: chloroform (90:10) solution. Lastly, $0.02 \mathrm{~mL}$ of an $0.1 \mathrm{~mol} \mathrm{~L}^{-1}$ ammonium formate solution was added to the final solution to form adduct ions consequently favoring ionization via $\left[\mathrm{TAG}+\mathrm{NH}_{4}\right]^{+}$and enhancing the analysis reproducibility. The final solution was infused into the mass spectrometer with a $10.0 \mathrm{~mL} \mathrm{~min}^{-1}$ flow. Data were automatically processed by MassLynx ${ }^{\mathrm{TM}} 4.1$ software.

The following conditions were employed for TAG analysis: capillary voltage of $3 \mathrm{kV}$, cone voltage of $20 \mathrm{~V}$, desolvation temperature of $200{ }^{\circ} \mathrm{C}$, and mass/charge range of $100-1200 \mathrm{~m} / z$. Different TAG species were analyzed.

\subsection{TAG identification}

The major TAGs detected by ESI-MS for each sample were identified using LAMES platform combined with the Lipid maps ${ }^{\circledR}$ data bank. The platform utilizes an algorithm that predicts the distribution of the FA moieties in the triacylglycerol structure and estimates the content of the specific TAG based on the FA composition of samples. ${ }^{32}$

\subsection{Statistical Analysis}

FA composition of samples was determined in triplicate and results were expressed as mean \pm standard deviation. GC-FID data were submitted to variance analysis (ANOVA) and compared by Tukey's test $(p<0.05)$, using Assistat 7.6 software. ${ }^{33}$

\section{Results and Discussion}

\subsection{Fatty acid composition of the lipid fractions}

Partition of the lipid fractions of EVOO by CLC utilized a chloroform: acetone (8:2) solution and purified methanol to separate non-polar and polar lipids, respectively. To elute non-polar lipids, $200 \mathrm{~mL}$ of the chloroform: acetone (8:2) solution was eluted and collected in four $50 \mathrm{~mL}$ fractions 
named FN1, FN2, FN3, and FN4, and stored for GC-FID analysis. For polar lipids, the same procedure was done, four $50 \mathrm{~mL}$ fractions of purified methanol, named FP1, FP2, FP3, and FP4, containing the polar lipids of extra virgin olive oil were collected and stored for fatty acid analysis by GC-FID.

Figure 1 presents the FA composition of neutral and polar lipid fractions of extra virgin olive oil.

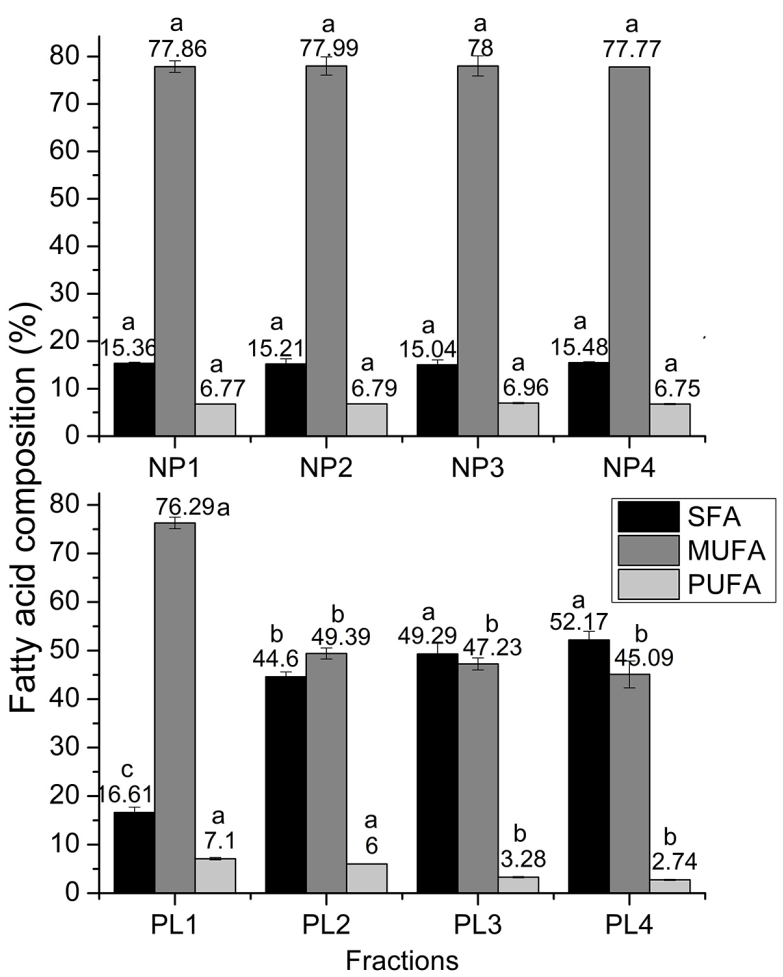

Figure 1. FA composition (\%) of non-polar and polar lipid fractions of extra virgin olive oil.

Regarding the polar lipid fraction, Figure 1 shows that throughout the four fractions (FP1-FP4), MUFA percentage decreased sharply, from $76.29 \%$ to $45.09 \%$, while SFA percentage increase significantly, from $16.61 \%$ to $52.17 \%$, indicating that in the polar lipid fraction SFAs have stronger interactions with the stationary phase while unsaturated fatty acids (UFA) demonstrated higher affinity towards the mobile phase. Thus, within the polar fraction, it is possible to acquire lipid fractions that contain a higher content of specific FAs, such as 18:1n-9 in FP1 and 16:0 in FP3. Mean data and standard deviation are also shown in the supplementary material (Table S.1).

As shown in table S.1 all four non-polar lipid fractions (FN1-FN4) of EVOO are composed mainly of oleic acid (18:1n-9), ranging from $76.35-76.77 \%$, and palmitic acid (16:0), ranging from 11.71-12.19\%, which is in agreement with the values obtained by Silveira et al. (2017). ${ }^{15}$ Furthermore, monounsaturated fatty acids (MUFAs) were the major FAs identified in FN1-FN4, ranging from 77.75$77.98 \%$, due to the high amount of $18: 1 \mathrm{n}-9$ in these fractions. Besides, there were no substantial differences in the FA composition of the neutral lipid fractions.
The fatty acids detected in $\mathrm{OO}$ are majorly responsible for the organoleptic and biological properties of the oil, as well as its numerous health benefits. For instance, the World Health Organization (WHO) recommends the consumption of $\mathrm{OO}$ for a diet rich in MUFAs since they are preferable over SFAs due to their capability of regulating cholesterol levels in the blood. ${ }^{34-35}$ Furthermore, oleic acid, the major FA of OO, has several health benefits such as helping control the secretory activity of both pancreas and liver, and decreasing the risk of developing gastric-duodenal ulcers and cardiovascular diseases. ${ }^{36}$ However, OO also has a substantial content of palmitic acid, which despite its nutritional benefits must be consumed with caution as SFA-rich diets are severely condemned for being attributed to the lipotoxicity of numeral organs and increasing the risk of developing diabetes and cardiovascular diseases as a result of inflammation and insulin resistance. Palmitic acid, in particular, may increase cholesterol e LDL-C plasmatic concentration in the organism. ${ }^{37-39}$ Nonetheless, the Food and Drug Administration (FDA) recommends consuming two spoons of $\mathrm{OO}$ daily. ${ }^{40}$

MUFAs were the major compounds in all nonpolar lipid classes analyzed, however, none of the FNs showed significant differences in their FA composition in comparison to other neutral fractions analyzed, which indicates that the chloroform: acetone (8:2) solution utilized may not be efficient to concentrate a specific FA. On the other hand, the purified methanol used as mobile phase to elute Fraction 02 demonstrated efficiency in concentrating predominantly SFA throughout collected FPs, while the higher percentages for MUFAs and PUFAs were obtained in the first polar lipid fraction.

\subsection{Triacylglycerol composition}

Although EVOO is composed predominantly of TAGs and FAs, the edible oil has numerous minor polar compounds, for instance, partial glycerides, hydrocarbons, tocopherols, pigments, sterols, alcohols, triterpenic acids, volatile compounds, phenolic compounds, and phospholipids.

Aiming to identify the lipid profile of each lipid fraction of EVOO, ESI-MS was applied since the technique is capable of providing results swiftly for a broad spectrum of polar molecules without requiring a sample preparation step before analysis, such as esterification/ transesterification reactions. Additionally, ESI-MS allows quick characterization of samples via fingerprinting.

TAGs of EVOO were identified and the main triacylglycerol was OOO, followed by POO, OOL, POL, and SOO, where O, P, L, and S refer to oleic, palmitic, linoleic, and stearic acids, respectively. Figure 2 illustrates the spectra of the four non-polar lipid fractions collected in the region of $100-1050 \mathrm{~m} / \mathrm{z}$.

For EVOO, the region of DAG and TAG predominance was $600-800 \mathrm{~m} / \mathrm{z}$ and $800-1050 \mathrm{~m} / \mathrm{z}$, respectively. The most 

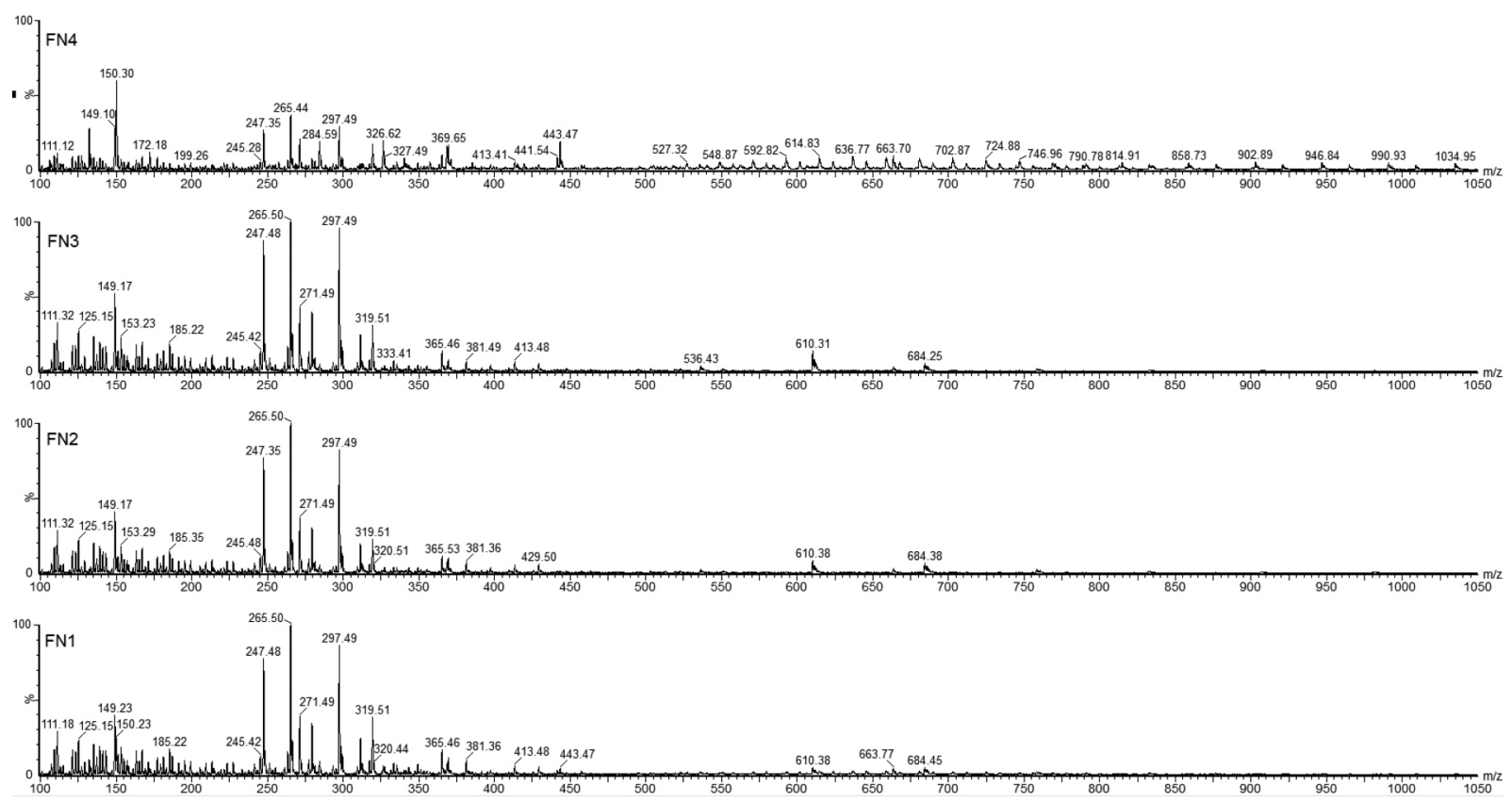

Figure 2. Lipid profile of non-polar lipid fractions FN1-FN4

intense ion peak in EVOO was $902 \mathrm{~m} / \mathrm{z}$ (OOO) which concurs with the results found by Silveira et al. (2017) $)^{15}$ where the same TAG exhibited the highest intensity.

Figure 3 demonstrates the mass spectra in the region of $100-1100 \mathrm{~m} / \mathrm{z}$ for the polar lipid fractions of EVOO.

As shown in figure 3 , as the volume of eluent permeating the column increased the intensity of MAGs, DAGs, and TAGs decreased.

Table 2 exhibits the estimated percentage for the major TAGs detected in each eluted polar and non-polar lipid fraction.

As shown by table 2, twenty-five TAGs were identified in the non-polar lipid fraction whereas twenty-seven TAGs were identified in the polar lipid fraction, except for FP1 which, in contrast to the other eluted polar lipid fractions, did not present TAGs MOP $(822 \mathrm{~m} / \mathrm{z})$ and MOO $(848 \mathrm{~m} / \mathrm{z})$.
Curiously, a TAG profile exceptionally similar to the nonpolar lipid fractions was observed for FP1 despite the changes to the eluent's strength. The similarity among the profiles of the non-polar fractions and FP1 was triggered by altering the eluent's polarity, which subsequently affected the differential migration of the constituents of olive oil owing to new interactions with the eluent and stationary phase. From table 2, the major triacylglycerols detected in the neutral lipid fraction of olive oil were OOO $(902 \mathrm{~m} / \mathrm{z})$ and POO $(876 \mathrm{~m} / \mathrm{z})$. These results concur with those by Silveira et al. (2017), ${ }^{15}$ Simas et al. $(2010) .{ }^{41}$ Besides POO $(876 \mathrm{~m} / \mathrm{z})$ and OOO $(902 \mathrm{~m} / \mathrm{z})$, the polar lipid fraction was also predominantly composed of SOO $(904 \mathrm{~m} / \mathrm{z})$ and POP $(850 \mathrm{~m} / \mathrm{z})$. Furthermore, the estimated concentration for TAGs in each lipid fraction substantiates the FA composition quantified for the respective samples, as demonstrated
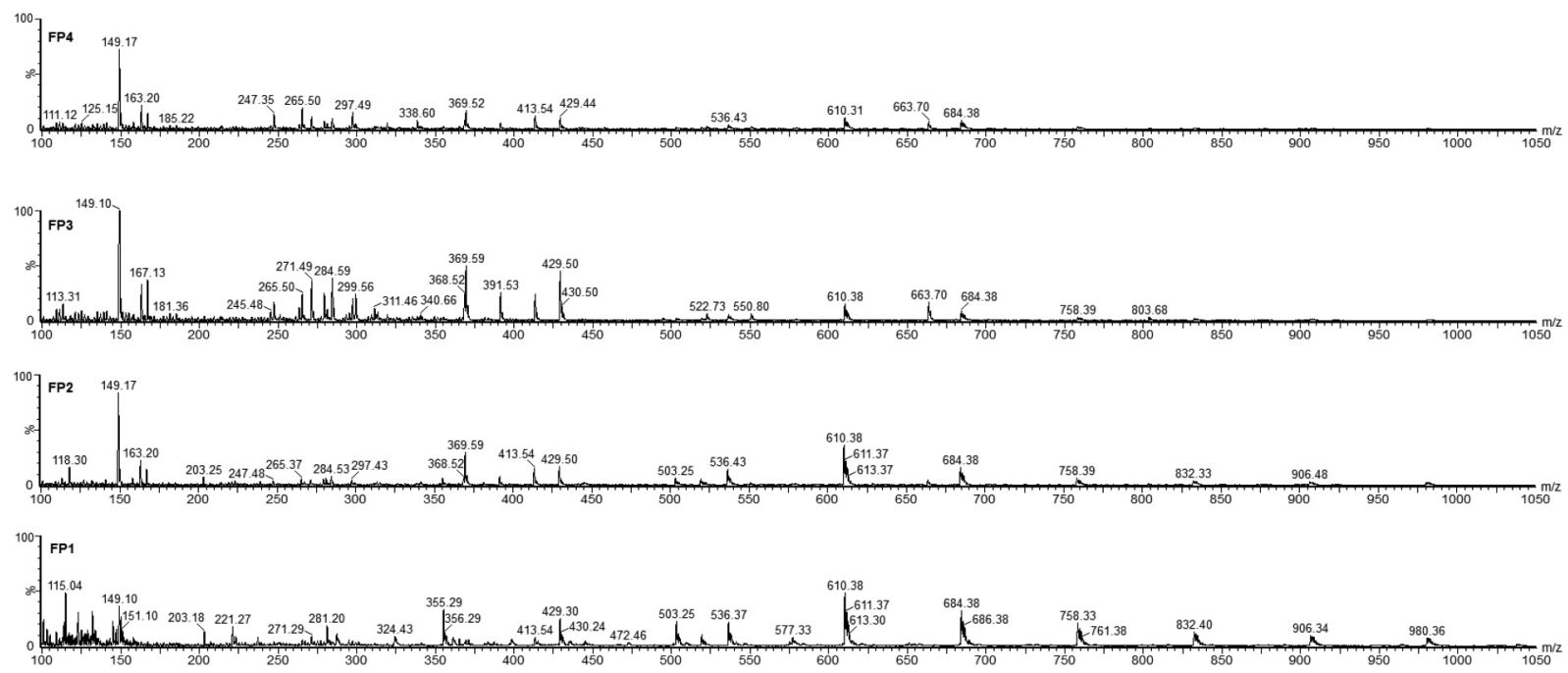

Figure 3. Lipid profile of polar lipid fractions FP1-FP4 
Table 2. TAG estimate (\%) on non-polar and polar lipid fractions of extra virgin olive oil detected by ESI (+)-MS and identified by LAMES software.

\begin{tabular}{|c|c|c|c|c|c|c|c|c|c|c|c|}
\hline \multirow{2}{*}{ Composition } & \multirow{2}{*}{ CN:DB } & \multirow{2}{*}{$m / z$} & \multirow{2}{*}{$\begin{array}{c}\text { TAG } \\
\text { assignment }\end{array}$} & \multicolumn{8}{|c|}{ TAG estimate (\%) } \\
\hline & & & & FN1 & FN2 & FN3 & FN4 & FP1 & FP2 & FP3 & FP4 \\
\hline $\mathrm{C}_{51} \mathrm{H}_{96} \mathrm{O}_{6}$ & $48: 1$ & 822 & MOP & $\mathrm{ND}$ & $\mathrm{ND}$ & $\mathrm{ND}$ & $\mathrm{ND}$ & $\mathrm{ND}$ & 3.142 & 0.593 & 0.563 \\
\hline $\mathrm{C}_{51} \mathrm{H}_{98} \mathrm{O}_{6}$ & $48: 0$ & 824 & PPP & 0.174 & 0.165 & 0.152 & 0.152 & 0.200 & 1.830 & 2.136 & 2.676 \\
\hline $\mathrm{C}_{53} \mathrm{H}_{98} \mathrm{O}_{6}$ & $50: 2$ & 848 & $\mathrm{PPoO}$ & 0.429 & 0.422 & 0.410 & 0.409 & 0.549 & 0.728 & $\mathrm{ND}$ & 2.035 \\
\hline $\mathrm{C}_{53} \mathrm{H}_{98} \mathrm{O}_{6}$ & $50: 2$ & 848 & POPo & ND & ND & ND & ND & ND & ND & 1.843 & $\mathrm{ND}$ \\
\hline $\mathrm{C}_{53} \mathrm{H}_{98} \mathrm{O}_{6}$ & $50: 2$ & 848 & MOO & $\mathrm{ND}$ & $\mathrm{ND}$ & $\mathrm{ND}$ & ND & $\mathrm{ND}$ & 3.057 & 0.500 & 0.420 \\
\hline $\mathrm{C}_{53} \mathrm{H}_{98} \mathrm{O}_{6}$ & $50: 2$ & 848 & PLP & 0.265 & 0.256 & 0.250 & 0.243 & 0.304 & 1.255 & 0.606 & 0.612 \\
\hline $\mathrm{C}_{53} \mathrm{H}_{100} \mathrm{O}_{6}$ & $50: 1$ & 850 & POP & 3.559 & 3.443 & 3.274 & 3.285 & 3.845 & 10.689 & 10.804 & 11.999 \\
\hline $\mathrm{C}_{53} \mathrm{H}_{102} \mathrm{O}_{6}$ & $50: 0$ & 852 & SPP & 0.111 & 0.107 & 0.106 & 0.106 & 0.136 & 1.771 & 3.676 & 4.510 \\
\hline $\mathrm{C}_{55} \mathrm{H}_{100} \mathrm{O}_{6}$ & $52: 3$ & 874 & PLO & 3.618 & 3.558 & 3.481 & 3.481 & 3.845 & 4.887 & 2.596 & 2.205 \\
\hline $\mathrm{C}_{55} \mathrm{H}_{100} \mathrm{O}_{6}$ & $52: 3$ & 874 & $\mathrm{PoOO}$ & $\mathrm{ND}$ & $\mathrm{ND}$ & $\mathrm{ND}$ & $\mathrm{ND}$ & $\mathrm{ND}$ & 0.710 & 1.553 & ND \\
\hline $\mathrm{C}_{55} \mathrm{H}_{100} \mathrm{O}_{6}$ & $52: 3$ & 874 & $\mathrm{OPoO}$ & 1.467 & 1.471 & 1.469 & 1.467 & 1.760 & ND & ND & 1.521 \\
\hline $\mathrm{C}_{55} \mathrm{H}_{102} \mathrm{O}_{6}$ & $52: 2$ & 876 & POO & 22.119 & 22.066 & 21.487 & 21.450 & 22.528 & 20.810 & 18.216 & 17.936 \\
\hline $\mathrm{C}_{55} \mathrm{H}_{104} \mathrm{O}_{6}$ & $52: 1$ & 878 & SOP & 1.517 & 1.492 & 1.511 & 1.516 & 1.743 & 6.893 & 12.395 & 13.483 \\
\hline $\mathrm{C}_{55} \mathrm{H}_{106} \mathrm{O}_{6}$ & $52: 0$ & 880 & SPS & 0.024 & 0.023 & 0.025 & 0.025 & 0.031 & 0.434 & 2.109 & 2.534 \\
\hline $\mathrm{C}_{57} \mathrm{H}_{96} \mathrm{O}_{6}$ & $54: 7$ & 894 & OLnO & 0.843 & 0.846 & 0.841 & 1.100 & 1.056 & 0.258 & 0.112 & 0.053 \\
\hline $\mathrm{C}_{57} \mathrm{H}_{100} \mathrm{O}_{6}$ & $54: 5$ & 898 & OLL & 0.846 & 0.846 & 0.897 & 0.840 & 0.907 & 0.424 & 0.122 & 0.084 \\
\hline $\mathrm{C}_{57} \mathrm{H}_{102} \mathrm{O}_{6}$ & $54: 4$ & 900 & OLO & 11.373 & 11.401 & 11.754 & 11.367 & 11.440 & 4.756 & 2.188 & 1.648 \\
\hline $\mathrm{C}_{57} \mathrm{H}_{104} \mathrm{O}_{6}$ & $54: 3$ & 902 & SLO & 0.709 & 0.709 & 0.757 & 0.731 & 0.809 & 1.576 & 1.490 & 1.238 \\
\hline $\mathrm{C}_{57} \mathrm{H}_{104} \mathrm{O}_{6}$ & $54: 3$ & 902 & OOO & 46.896 & 47.135 & 47.015 & 46.687 & 44.001 & 13.505 & 10.238 & 8.936 \\
\hline $\mathrm{C}_{57} \mathrm{H}_{106} \mathrm{O}_{6}$ & $54: 2$ & 904 & $\mathrm{SOO}$ & 4.769 & 4.781 & 4.959 & 4.950 & 5.104 & 6.710 & 10.449 & 10.077 \\
\hline $\mathrm{C}_{57} \mathrm{H}_{108} \mathrm{O}_{6}$ & $54: 1$ & 906 & AOP & 0.161 & 0.158 & 0.154 & 0.153 & 0.165 & 0.265 & 0.132 & 0.210 \\
\hline $\mathrm{C}_{57} \mathrm{H}_{108} \mathrm{O}_{6}$ & $54: 1$ & 906 & SOS & 0.149 & 0.149 & 0.160 & 0.159 & 0.180 & 0.844 & 3.555 & 3.788 \\
\hline $\mathrm{C}_{59} \mathrm{H}_{110} \mathrm{O}_{6}$ & $56: 2$ & 932 & $\mathrm{AOO}$ & 0.506 & 0.507 & 0.505 & 0.500 & 0.483 & 0.258 & 0.112 & 0.158 \\
\hline $\mathrm{C}_{59} \mathrm{H}_{112} \mathrm{O}_{6}$ & $56: 1$ & 934 & $\mathrm{BhOP}$ & 0.054 & 0.052 & 0.051 & 0.051 & 0.110 & 3.398 & 3.350 & 3.138 \\
\hline $\mathrm{C}_{61} \mathrm{H}_{114} \mathrm{O}_{6}$ & $58: 2$ & 960 & BhOO & 0.168 & 0.169 & 0.168 & 0.167 & 0.322 & 3.398 & 2.824 & 2.345 \\
\hline $\mathrm{C}_{61} \mathrm{H}_{116} \mathrm{O}_{6}$ & $58: 1$ & 962 & BhOS & 0.011 & 0.011 & 0.011 & 0.011 & 0.025 & 0.854 & 1.922 & 1.763 \\
\hline $\mathrm{C}_{61} \mathrm{H}_{116} \mathrm{O}_{6}$ & $58: 1$ & 862 & LgOP & ND & $\mathrm{ND}$ & ND & $\mathrm{ND}$ & ND & 3.403 & 2.680 & $\mathrm{ND}$ \\
\hline $\mathrm{C}_{61} \mathrm{H}_{116} \mathrm{O}_{6}$ & $58: 1$ & 862 & POLg & 0.054 & 0.052 & 0.103 & 0.255 & 0.110 & $\mathrm{ND}$ & $\mathrm{ND}$ & 2.629 \\
\hline $\mathrm{C}_{63} \mathrm{H}_{118} \mathrm{O}_{6}$ & $60: 2$ & 970 & LgOO & 0.168 & 0.169 & 0.336 & 0.835 & 0.322 & 3.313 & 2.260 & 1.965 \\
\hline $\mathrm{C}_{63} \mathrm{H}_{120} \mathrm{O}_{6}$ & $60: 1$ & 990 & LgOS & $\mathrm{ND}$ & ND & ND & $\mathrm{ND}$ & $\mathrm{ND}$ & 0.833 & 1.538 & ND \\
\hline $\mathrm{C}_{63} \mathrm{H}_{120} \mathrm{O}_{6}$ & $60: 1$ & 990 & SOLg & 0.011 & 0.011 & 0.024 & 0.059 & 0.025 & $\mathrm{ND}$ & $\mathrm{ND}$ & 1.477 \\
\hline
\end{tabular}

**CN:DB: carbon number/number of double bonds of the three fatty acid moieties. ND: Not detected. P: palmitic acid (16:0); Po: palmitoleic acid (16:1n-7); S: stearic acid (18:0); O: oleic acid (18:1n-9); L: linoleic acid (18:2n-6); Ln: $\gamma$-linolenic acid (18:3n-6); A: arachidic acid (20:0); Bh: docosanoic acid (22:0); Lg: lignoceric acid (24:0).

by Table 2. OOO intensity in the non-polar lipid fraction was substantially higher than that found for the same triacylglycerol in the polar lipid fraction, which indicates that the eluent employed to elute the neutral lipid fraction, a solution of chloroform: acetone (8:2), offered a better separation and higher intensities due to its greater selectivity compared to purified methanol. Moreover, as the non-polar lipid fractions were collected POO intensity increased and OOO decreased.

Also, the neutral lipid fraction displayed greater intensities for the major TAGs of olive oil in comparison with the polar lipid fraction because of the eluent's polarity, the interaction between the stationary phase and analytes, and the effect of altering the eluent's strength on its selectivity, since the results indicate that free FAs were eluted first, followed by flavonoids, steroids, phenolic acids, and hydrocarbons. ${ }^{42}$

\section{Conclusion}

Data provided by GC-FID and ESI-MS analysis demonstrated that classic liquid chromatography can be applied as a sample preparation technique to partition the lipid classes in EVOO. Furthermore, the fatty acid analysis indicated a greater content of MUFAs in the neutral lipid fraction in comparison with the polar lipid fraction which was richer in SFAs. These results were concurred by ESI-MS 
data since the major TAGs of EVOO were detected with greater intensities in the non-polar lipid fraction of the oil.

\section{Acknowledgments}

The authors thank Conselho Nacional de Desenvolvimento Científico e Tecnológico, Brazil (CNPq), Coordenação de Aperfeiçoamento de Pessoal de Nível Superior (CAPES), and Fundação Araucária de Apoio ao Desenvolvimento Científico e Tecnológico do Paraná for their financial support.

\section{Conflict of interest}

No potential conflict of interest was reported by the authors.

\section{References}

1. Rallo, L.; Díez, C. M.; Morales-Sillero, A.; Miho, H.; PriegoCapote, F.; Rallo, P.; Quality of olives: A focus on agricultural preharvest factors. Scientia Horticulturae 2018, 233, 491. [CrossRef]

2. Foscolou, A.; Critselis, E.; Panagiotakos, D.; Olive oil consumption and human health: A narrative review. Maturitas 2018, 118, 60. [CrossRef] [PubMed]

3. Nomikos, N. N.; Nomikos, G. N.; Kores, D. S.; The use of deep friction massage with olive oil as a means of prevention and treatment of sports injuries in ancient times. Archives of Medical Science 2010, 6, 642. [CrossRef] [PubMed]

4. Espadas-Aldana, G.; Vialle, C.; Belaud, J. P.; Vaca-Garcia, C.; Sablayrolles, C.; Analysis and trends for Life Cycle Assessment of olive oil production. Sustainable Production and Consumption 2019, 19, 21. [CrossRef]

5. International Olive Council; What we do: Economic affair promotion unit. Available in $<$ https://www.internationaloliveoil. org/what-we-do/economic-affairs-promotion-unit/>. Accessed in: $31^{\text {th }}$ may 2021.

6. Borges, H.; López, C. L.; Pereira, A. J.; Cabrera-Vique, C.; Seiquer, I.; Comparative analysis of minor bioactive constituents (CoQ10, tocopherols and phenolic compounds) in Arbequina extra virgin olive oils from Brazil and Spain. Journal of Food Composition and Analysis 2017, 63, 47. [CrossRef]

7. International Olive Council; Olive World: Olive Oil \& Health. Disponível < https://www.internationaloliveoil.org/olive-world/ olive-oil-health $/>$. Accessed in: $31^{\text {th }}$ may 2021.

8. Zago, L.; Squeo, G.; Bertoncini, E. I.; Difonzo, G.; Caponio, F.; Chemical and sensory characterization of Brazilian virgin olive oils. Food Research International 2019, 126, 108588. [CrossRef] [PubMed]

9. Instituto Brasileiro de Olivicultura; Projeção do mercado oleícola para os próximos anos. Available in $<$ https://www.ibraoliva.com. br>. Accessed in: 31 th may 2021.
10. Boskou, D.; Olive oil: chemistry and technology. 1st Ed. Elsevier: Amsterdam, 2015. [CrossRef]

11. Nelson, D. L.; Cox, M. M.; Princípios de Bioquímica de Lehninger, 6a Ed., Artmed: Maringá, 2014.

12. Visentainer V. J.; Souza E. M.; Colesterol da Mesa ao Corpo, 2nd Ed., Eduem: Maringá, 2012.

13. Indelicato, S.; Bongiorno, D.; Pitonzo, R.; Di Stefano, V.; Calabrese, V.; Indelicato, S.; Avellone, G.; Triacylglycerols in edible oils: Determination, characterization, quantitation, chemometric approach and evaluation of adulterations. Journal of Chromatography A 2017, 1515, 1. [CrossRef] [PubMed]

14. Portarena, S.; Leonardi, L.; Scartazza, A.; Lauteri, M.; Baldacchini, C.; Farinelli, D.; Famiani, F.; Ciolfi, M.; Brugnoli, E.; Combining analysis of fatty acid composition and $\delta^{13} \mathrm{C}$ in extra-virgin olive oils as affected by harvest period and cultivar: Possible use in traceability studies. Food Control 2019, 105, 151. [CrossRef]

15. Silveira, R.; Vágula, J. M.; Figueiredo, L. I.; Claus, T.; Galuch, M. B.; Junior, O. O. S.; Visentainer, V. J.; Rapid methodology via mass spectrometry to quantify addition of soybean oil in extra virgin olive oil: A comparison with traditional methods adopted by food industry to identify fraud. Food Research International 2017, 102, 43. [CrossRef] [PubMed]

16. Marini, F.; Triacylglycerols: Characterization and Determination. Encyclopedia of Food and Health 2016, 1, 345. [CrossRef]

17. Beneito-Cambra, M.; Moreno-González, D.; García-Reyes, J. F.; Bouza, M.; Gilbert-López, B.; Molina-Díaz, A.; Direct analysis of olive oil and other vegetable oils by mass spectrometry: a review. TrAC Trends in Analytical Chemistry 2020, 1, 116046. [CrossRef]

18. Hewavitharana, G. G.; Perera N. D.; Navaratne, S. B.; Wickramasinghe, I.; Extraction methods of fat from food samples and preparation of fatty acid methyl esters for gas chromatography: A review, Arabian Journal of Chemistry 2020, 13, 6865. [CrossRef]

19. Silvestre, I. C. C.; Santos, L. M. J.; Lima, L. F. C. J.; Zagatto, A. G. E.; Liquid-liquid extraction in flow analysis: A critical review, Analytica Chimica Act 2009, 652, 54. [CrossRef] [PubMed]

20. Johnston, J. J.; Ghanbari, H. A.; Wheeler, W. B.; Kirk, J. R.; Characterization of shrimp lipids. Journal of food science 1983, 48, 33. [CrossRef]

21. Collins C. H.; Braga G. L.; Bonato O. S.; Fundamentos de Cromatografia. 1st ed, Unicamp: Campinas, 2006.

22. Pacheco, S.; Borguini, R. G.; Santiago, M. C. P. A.; Nascimento, L. S. M.; Godoy, R. L. O.; História da Cromatografia Líquida. Revista Virtual da Química 2015, 7, 1225. [CrossRef]

23. Olmo-García, L.; Polari, J. J.; Li, X.; Bajoub, A.; FernándezGutiérrez, A.; Wang, S. C.; Carrasco-Pancorbo, A.; Deep insight into the minor fraction of virgin olive oil by using LC-MS and GC-MS multi-class methodologies. Food Chemistry 2018, 261, 184. [CrossRef] [PubMed]

24. Bajoub, A.; Hurtado-Fernández E.; Ajal, E. A.; Ouazzani, N.; Gutiérrez, A. F.; Carrasco-Pancorbo, A.; Comprehensive 3-year study of the phenolic profile of Moroccan monovarietal virgin olive oils from the Meknès region. Journal of Agricultural and Food Chemistry 2015, 17, 4376. [CrossRef] [PubMed] 
25. Capriotti, A. L.; Cavaliere, C.; Crescenzi, C.; Foglia, P.; Nescatelli, R.; Samperi, R.; Laganà, A.; Comparison of extraction methods for the identification and quantification of polyphenols in virgin olive oil by ultra-HPLC-QToF mass spectrometry. Food Chemistry 2014, 158, 392. [CrossRef] [PubMed]

26. Tasioula-Margari, M.; Okogeri, O.; Simultaneous determination of phenolic compounds and tocopherols in virgin olive oil using HPLC and UV detection. Food Chemistry 2001, 74, 377. [CrossRef]

27.. Cabral, E. C.; Cruz, G. F.; Simas, R. C.; Sanvido, G. B.; Gonçalves, L. V.; Leal, R. V. P.; Eberlin, M. N.; Typification and quality control of the Andiroba (Carapa guianesis) oil via mass spectrometry fingerprint. Analytical Methods 2013, 5, 1357. [CrossRef]

28. Lerma-García, M. J.; Lusardi, R.; Chiavaro, E.; Cerretani, L.; Bendini, A.; Ramis-Ramos, G.; Simo-Alfonso, E. F.; Use of triacylglycerol profiles established by high performance liquid chromatography with ultraviolet-visible detection to predict the botanical origin of vegetable oils. Journal of Chromatography A 2011, 1218, 7521. [CrossRef] [PubMed]

29. Agozzino, P.; Avellone, G.; Bongiorno, D.; Ceraulo, L.; Indelicato, S.; Indelicato, S.; Vèkey, K.; Determination of the cultivar and aging of Sicilian olive oils using HPLC-MS and linear discriminant analysis. Journal of mass spectrometry 2010 , 45, 989. [CrossRef] [PubMed]

30. Leskinen, H.; Suomela, J. P.; Kallio, H.; Quantification of triacylglycerol regioisomers in oils and fat using different mass spectrometric and liquid chromatographic methods. Rapid Communications in Mass Spectrometry 2007, 21, 2361. [CrossRef] [PubMed]

31. International Organization for Standardization, ISO. 5509; Animal and vegetable fats and oils - preparation of methyl esters of fatty acids. 2000. [Link]

32. Antoniosi Filho, N. R.; Mendes, O. L.; Lanças, F. M.; Computer prediction of triacylglycerol composition of vegetable oils by HRGC. Chromatographia 1995, 40, 557. [CrossRef]
33. Silva, F. A. S.; The ASSISTAT Software: Statistical Assistance; Universidade Federal de Campina Grande, Brasil, 1996.

34. Organização Mundial de Saúde. Dieta saudável. Available in: $<$ http://who.int/mediacentre/factsheets/fs394/en/>. Accessed in: 31 maio 2021.

35. Piroddi, M.; Albini, A.; Fabiani, R.; Giovannelli, L.; Luceri, C.; Natella, F.; Rosignoli, P.; Rossi, T.; Taticchi, A.; Servili, M.; Galli, F.; Nutrigenomics of extra-virgin olive oil: A review. Biofactors 2016, 43, 17. [CrossRef] [PubMed]

36. Santosa, M.; Clow, E. J.; Sturzenberger, N. D.; Guinard, J. X.; Knowledge, beliefs, habits and attitudes of California consumers regarding extra virgin olive oil. Food Research International 2013, 54, 2104. [CrossRef]

37. Maldonado-Ruiz, R.; Montalvo-Martínez, L.; Fuentes-Mera, L.; Camacho, A.; Microglia activation due to obesity programs metabolic failure leading to type two diabetes. Nutrition \& diabetes 2017, 7, e254. [CrossRef] [PubMed]

38. Nogueira- De- Almeida, C. A.; de Castro, G. A.; Effects of heat treatment by immersion in household conditions on olive oil as compared to other culinary oils: a descriptive study. International Journal of Food Studies 2018, 7, 89. [CrossRef]

39. Chemin, S. M. S. S.; Mura, J. D. P.; Tratado de Alimentação, Nutrição e Dietoterapia, 3a ed., ROCA: São Paulo, 2016.

40. Food and Drug Administration; FDA Completes Review of Qualified Health Claim Petition for Oleic Acid and the Risk of Coronary Heart Disease, Roma, 2018. [Link]

41. Simas, R. C.; Catharino, R. R.; Cunha, I. B.; Cabral, E. C.; Barrera-Arellano, D.; Eberlin, M. N.; Alberici, R. M.; Instantaneous characterization of vegetable oils via TAG and FFA profiles by easy ambient sonic-spray ionization mass spectrometry. Analyst 2010, 135, 738. [CrossRef] [PubMed]

42. Catharino, R. R.; Haddad, R.; Cabrini, L. G.; Cunha, I. B.; Sawaya, A. C.; Eberlin, M. N.; Characterization of vegetable oils by electrospray ionization mass spectrometry fingerprinting: classification, quality, adulteration, and aging. Analytical chemistry 2005, 77, 7429. [CrossRef] [PubMed] 